\title{
Síndrome de Beckwith-Wiedemann
}

\author{
Eva Buller Viqueira, Rosalía Ureba Rubio, Juana Cabello Pulido.
}

Centro de Salud Gonzalo Pérez Fabra, Paterna de Rivera, Cádiz, España

Correspondencia:

Eva Buller Viqueira.

Correo electrónico:

miji_77@yahoo.com

Recibido el 6 de diciembre de 2013.

Aceptado para su publicación el 15 de enero de 2014.

\section{RESUMEN}

El síndrome de Beckwith-Wiedemann (SBW) es un síndrome congénito multisistémico consistente en hipoglucemia y macrosomía, siendo los más comunes macroglosia, peso elevado al nacer, onfalocele y visceromegalia.

Presentamos el caso de una niña de cinco años con SBW que acude a nuestro centro de salud por seguimiento de su patología.

Palabras clave: Síndrome de Beckwith-Wiedemann. Macroglosia. Gigantismo.

\section{ABSTRACT}

\section{Beckwith-Wiedemann Syndrome}

Beckwith-Wiedemann Syndrome (BWS) is a congenital multisystemic syndrome characterized by hypoglycemia and macrosomia, being the most common macroglossia, high weight at birth, omphalocele and visceromegaly.

The present is the case of a five year-old girl with BWS who comes to the healthcare center to follow up of her pathology.

Keywords: Beckwith-Wiedemann syndrome. Macroglossia. Gigantism.

\section{INTRODUCCIÓN}

Hans-Rudolf Wiedemann describió un caso familiar consistente en onfalocele y macroglosia en 1964. Posteriormente Bruce Beckwith describió otros casos similares. Fue bautizado con el nombre de síndrome de Beckwith-Wiedemann (SBW). Se trata de un síndrome congénito, multisistémico, consistente en hipoglucemia, hipercrecimiento, macroglosia, peso elevado al nacer, defectos de la pared abdominal y visceromegalia. Es el síndrome pediátrico más común que implica hipercrecimiento. Existe una predisposición a desarrollo tumoral embrionario.

Causado por una alteración genética en un dominio con imprinting 11p15.5, aunque como veremos más adelante su herencia es más compleja. La incidencia de esta patología es de uno entre 13.700 nacidos vivos y mayor entre niños nacidos por fertilización in vitro.

\section{OBSERVACIONES CLÍNICAS}

Presentamos el caso de una niña de cinco años con diagnóstico de SBW. La paciente acude a consulta para seguimiento de su patología. Al nacer presenta gigantismo, hepatomegalia, discreta nefromegalia, macroglosia, onfalocele severo, hipoglucemia neonatal y poliglobulia. El estudio genético fue informado como patrón de mutilación alterado de los dominios KvDMRy 
H19DMR, que coincide con una disomía uniparental de la región cromosómica 11p15, diagnóstico de síndrome de SBW.

Desde su nacimiento se le realizan controles de somatometría, ecografía abdominal, hemograma, bioquímica, péptido $\mathrm{C}$, insulina, alfa-fetoproteína y HCG. Ha sido intervenida de onfalocele. Está en tratamiento con diazóxido para las hipoglucemias y en programa de atención temprana con apoyo de logopeda, con buena evolución. Se ha intentado retirar su tratamiento con diazóxido sin éxito.

Actualmente está de alta de atención temprana, en seguimiento por logopeda y con una integración social y escolar buena. Los controles de sus glucemias con diazóxido son óptimos. Muy buena evolución de sus percentiles, normalizándose (Figura 1).

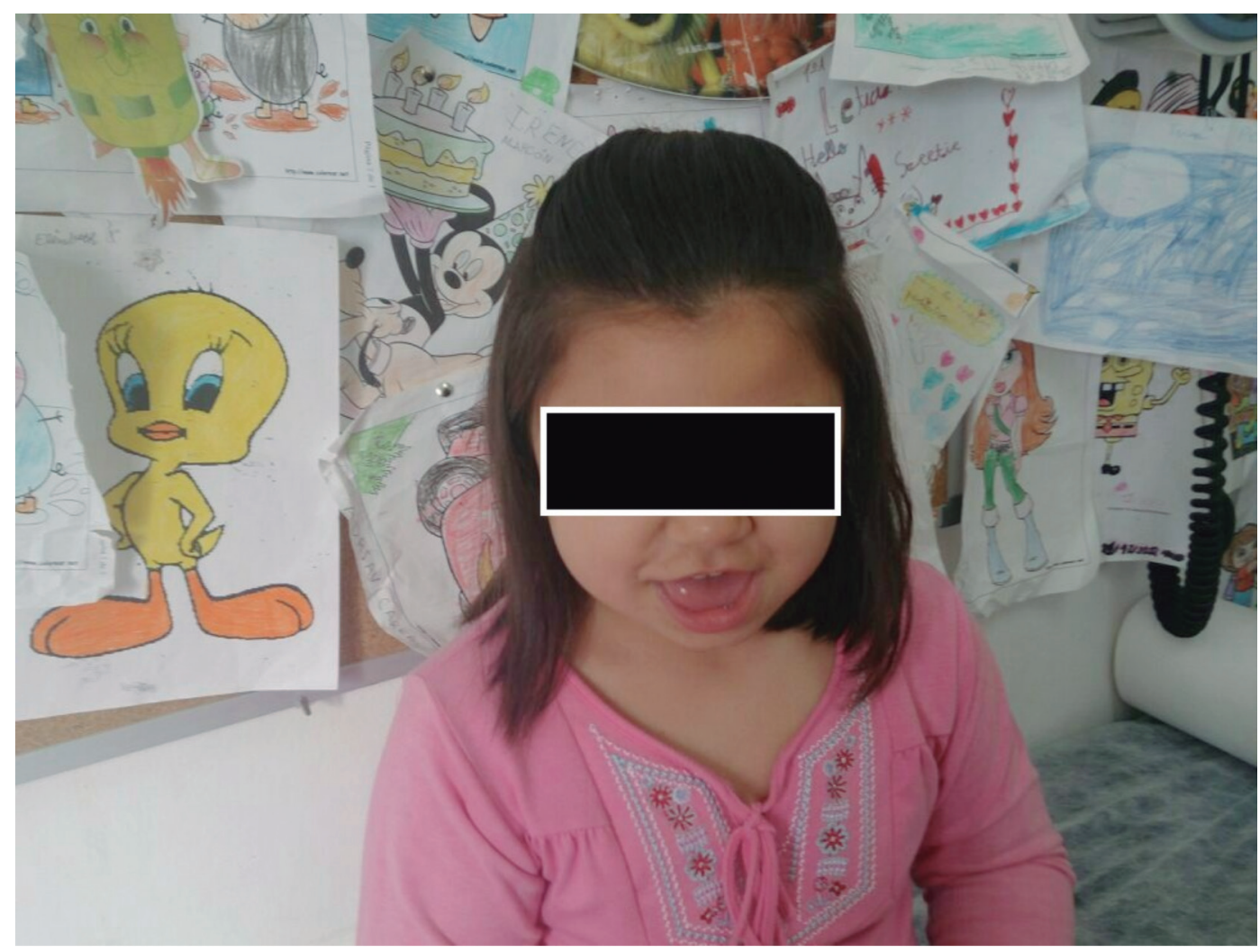

Figura 1. Paciente diagnosticada con Síndrome de Beckwith-Wiedemann

\section{CRITERIOS MAYORES}

- Macroglosia

- Defectos de la pared abdominal (onfalocele, hernia umbilical, diástasis de los rectos abdominales)

- Peso prenatal y/o postnatal superior al percentil 90

\section{CRITERIOS MENORES}

- Signos auriculares característicos (pliegues en reborde posterior del hélix, identiciones)

- Nevus flammeus facial

- Hipoglucemia

- Nefromegalia

- Hemihipertrofia

Tabla 1. Criterios diagnósticos según Elliot y cols. ${ }^{4}$ 


\section{COMENTARIOS}

El SBW es un síndrome congénito con una incidencia de uno entre 13.700 nacidos vivos, siendo mayor en niños engendrados con técnicas de reproducción asistida. No existe predilección por la raza ni por la edad. En cuanto a sexo, la incidencia es igual, salvo en los casos de gemelos monocigóticos en los que hay mayor incidencia en las mujeres. Uno de cada cinco casos fallece por complicaciones propias de la patología.

Las causas genéticas son muy complejas. La impronta genómica o imprinting es el fenómeno por el cual un gen se expresa de una manera o de otra según se herede del padre o de la madre. Alteraciones a nivel del cromosoma 11, particularmente de los genes que sufren imprinting, son los causantes del SBW. Aproximadamente el $50 \%$ de los casos se dan por alteraciones en la metilación. En la región 15.5 del brazo $p$ del cromosoma 11 existen los genes CDKN1C, H19, IGF2 y el KCNQ1OT1, entre otros, implicados en el crecimiento. Las regiones del control del imprinting (ICR) se encargan de la metilación de estos genes. Una metilación anormal altera la regulación del crecimiento provocando la macrosomía. Entre 10-20\% de los casos se da por una disomía uniparental paternal (dos copias paternas de los genes imprinting). Existen casos de mutaciones del gen CDKN1C, translocaciones o duplicaciones del material genético. Un $85 \%$ de los casos son esporádicos con un solo familiar afecto, en cambio en un 10-15\% la herencia sigue un patrón autosómico dominante ${ }^{1}$.

Existe un crecimiento aumentado durante la segunda mitad del embarazo, con fetos grandes para su edad gestacional. Algunos autores describen polihidramnios y placentomegalia ${ }^{2}$. En los primeros años de vida presentan percentiles en torno al 97 en cuanto a talla y peso, y el perímetro craneal cercano al 50. Los percentiles comienzan a bajar alrededor de los 8 años, normalizándose en la edad adulta. Existen casos de hemihipertrofia. Es el síndrome pediátrico más común que implica hipercrecimiento ${ }^{3}$.

Son también frecuentes los defectos de la pared abdominal, tipo onfalocele, hernia umbilical y diástasis de los rectos, visceromegalia implicando uno o más órganos. La citomegalia adrenocortical fetal es patognomónica del SBW. La macroglosia es una de las malformaciones más frecuentes y puede originar graves repercusiones en el periodo neonatal. Pueden también presentar pliegues y surcos del lóbulo auricular, nevus flammeus facial u ojos prominentes. Otros hallazgos son malformaciones cardiacas. El patrón clínico es muy variable.

Existe una predisposición a tumores embrionarios, aumentado respecto a la normalidad en un $7 \%$. Se suelen diagnosticar antes de los 8-10 años de vida. Los más comunes son el tumor de Wilms $(50 \%)$ y el hepatoblastoma y, con menos frecuencia, rabdomiosarcoma, carcinoma adrenocortical y neuroblastomas. Existe un $30 \%$ más de riesgo de desarrollar tumores en los casos de pacientes con hemihipertrofia ${ }^{3}$.

Elliot y cols. ${ }^{4}$ han establecido unos criterios diagnósticos para el síndrome (tabla 1). Implica la existencia de tres criterios mayores o dos mayores y tres criterios menores.

Es muy importante el diagnóstico en pacientes con menor expresividad fenotípica por el alto riesgo asociado a desarrollar tumores embrionarios y por las hipoglucemias. El seguimiento en el SBW consiste en cirugía de los defectos de la pared abdominal, screening de hipoglucemia y tratamiento si precisa, screening tumoral y somatometría. Pueden precisar cirugía reductora de la lengua por dificultad para la ingesta u obstrucción de la vía aérea. Ha de vigilarse la posibilidad de apnea del sueño. En ocasiones suelen necesitar el apoyo de logopedas y odontólogos.

EI SBW tiene una baja incidencia que puede estar sesgada por la falta de diagnóstico en casos de menor expresividad clínica. Es una enfermedad que precisa de seguimiento cercano por su alta predisposición a tumores y por los casos de hipoglucemia.

\section{BIBLIOGRAFÍA}

1. Begemann M, Spengler S, Gogiel M, Grasshoff U, Bonin M, Betz RC et al. Clinical significance of copy number variations in the 11p15.5 imprinting control regions: new cases and review of the literature. J Med Genet. 2012;49(9):54753.

2. Arroyo Carrera I, Martínez-Frías ML, Egüés Jimeno J, García Martínez MJ, Eloína Cimadevilla Sánchez C, Bermejo Sánchez E. Síndrome de Wiedemann-Beckwith: Análisis clínico-epidemiológico de una serie consecutiva de casos en España. An Esp Pediatr 1999;50:161-165.

3. Weksberg R, Shuman C, Beckwith JB. Beckwith-Wiedemann syndrome. Eur J Hum Genet. 2010;18(1):8-14.

4. Elliot M, Bayly R, Cole T, Temple IK, Maher ER. Clinical features and natural history of Beckwith-Wiedemann Syndrome. Am J Med Genet 1995;56:366-73. 